\title{
DISCUTINDO O PAPEL DO FUNCIONAL NO SOCIOFUNCIONALISMO
}

\author{
DISCUSSING THE ROLE OF FUNCTIONALISM \\ IN SOCIOFUNCTIONALISM
}

\author{
Guilherme Henrique May \\ Mestrando do Programa de Pós-graduação em Linguística UFSC/CNPq
}

\begin{abstract}
Resumo
Faço algumas considerações a respeito da interface teórica que articula princípios da sociolinguística variacionista e do funcionalismo voltado aos estudos da gramaticalização e que vem sendo denominada no Brasil por sociofuncionalismo. Esboço, neste momento, um quadro inicial de contribuições que uma perspectiva funcional da linguagem traz ao modelo teórico-metodológico da sociolinguística variacionista na configuração da proposta sociofuncionalista, com a discussão de alguns pontos que se assumem no trabalho sociolinguístico que acredito ganharem nova perspectiva ao entrarem em cena certos pressupostos funcionalistas.
\end{abstract}

Palavras-chave: Sociofuncionalismo; Linguística funcional; Sociolinguística; Convergências teóricas.

\begin{abstract}
In this paper I discuss a few points regarding a theoretical interface that combines principles from variationist sociolinguistics and functionalist studies on grammaticalization, known in Brazil as 'sociofunctionalism'. I suggest an initial set of contributions that a functional approach towards language brings to variationist sociolinguistics, by means of discussing some points of view that are taken in sociolinguistics which I believe gain new perspective when one considers certain functionalist assumptions.
\end{abstract}

Keywords: Sociofunctionalism; Functional linguistics; Sociolinguistics; Theoretical convergencies.

\section{INTRODUÇÃO}

Busco neste artigo $^{1}$ tecer algumas considerações a respeito da interface teórica que vem sendo denominada no Brasil por sociofuncionalismo, ligadas não à análise de algum objeto sob este quadro, mas justamente a seu aspecto teórico híbrido, um hibridismo decorrente da aproximação de duas vertentes teóricas de origens distintas, quais sejam, a sociolinguística variacionista (WEINREICH; LABOV; HERZOG, 1968; LABOV, 1972; 1982; 1994; 2001) e o funcionalismo voltado aos estudos da gramaticalização (GIVÓN, 1984; 1993; 1995; 2001; 2002; 2005; HOPPER, 1991; HEINE, 2003, entre

\footnotetext{
${ }^{1}$ Agradeço aos colegas da disciplina de Sociofuncionalismo, à Prof ${ }^{a}$ Edair Görski e aos avaliadores deste artigo pelos comentários e sugestões.
} 
outros) ${ }^{2}$.

Apesar de estudos que podem ser cunhados de sociofuncionalistas já virem sendo realizados há algum tempo no Brasil (PAREDES DA SILVA, 1993; NEVES, 1999; NARO; BRAGA, 2000; entre outros), apenas mais recentemente essa aproximação teórica tem sido debatida com mais fôlego (TAVARES, 2003; GÖRSKI; TAVARES, a publicar): consideram-se os pontos convergentes entre as duas propostas de análise, os divergentes, enfim, a possibilidade de se traçar "uma conversa na diferença" (PIRES DE OLIVEIRA, 1999). Parto aqui do pressuposto de que sim, embora haja pontos de conflito entre certos postulados variacionistas e funcionalistas - os quais, vale notar, não serão abordados aqui -, é tanto possível quanto desejável uma aproximação entre as duas correntes. Ora, por que desejável? Dessa afirmação decorre que somente o olhar sociolinguístico ou somente o funcionalista seriam incompletos frente a seus objetos; seria esse o caso? Não ouso uma postura tão radical, visto que tanto a sociolinguística quanto o funcionalismo linguístico vêm progredindo nas últimas décadas e nos oferecendo análises cada vez mais coerentes de inúmeros fenômenos ligados às línguas naturais. Contudo, defendo que a interface seja interessante no que uma perspectiva amplia os horizontes da outra, fazendo surgir uma terceira proposta, mais ampla, que nos oferece ainda mais ferramentas para que cerquemos nosso objeto satisfatoriamente (e não é isso, afinal, o que buscamos?).

Aqui, trato desse encontro teórico sob um viés específico: o de como, na constituição da proposta sociofuncionalista, alguns princípios do trabalho sociolinguístico podem ser enriquecidos a partir da consideração de princípios tradicionalmente funcionalistas ${ }^{3}$. Esboço, portanto, um quadro inicial dessas contribuições, apresentando antes algumas posições do debate que cerca a aproximação de teorias linguísticas no Brasil. Passo a uma apresentação da sociolinguística e de como ela vem lidando com a variação em níveis além do fonológico, e de como questões funcionais passaram a ganhar espaço no modelo. Sigo, então, com o objetivo de apresentar certos pontos assumidos na sociolinguística variacionista que acredito ganharem nova perspectiva ao consideraremse certos pressupostos funcionalistas, e que certamente entram em jogo ao propor-se um fazer sociofuncionalista.

\section{REVISITANDO O DEBATE}

Os chamados “casamentos” entre teorias já não são novidade nos estudos linguísticos brasileiros, e seus prós e contras vêm sendo discutidos por diversos autores. Da década de 1980, temos o conhecido debate iniciado por Fernando Tarallo; este, ao apresentar Zelig, seu linguista-camaleão, sugere que "uma certa dosagem de 'falta' de personalidade acirradamente teórica poderá levar o lingüista a resultados mais condizentes com os fatos que se propõe a analisar” (1986, p. 128). Apesar de para alguns essa postura parecer bastante plausível, a discussão não é pacífica; Borges Neto respondeu a Tarallo no ano seguinte, nestes termos:

\footnotetext{
${ }^{2}$ Outras sociolinguísticas podem encontrar outros funcionalismos, mas para os efeitos deste artigo limitome a esta união específica, uma que vem se mostrando frutífera nos últimos anos.

${ }^{3}$ É claro que, no casamento sociofuncionalista, a parte funcional também ganha com o olhar e as ferramentas variacionistas. Essa, entretanto, é uma direção de análise distinta da que faço por ora.
} 
Um programa de investigação científica nos pretende dar uma compreensão unificada da realidade, permitindo-nos predizer o comportamento de um objeto em diferentes situações. A explicação de diferentes aspectos de um fenômeno através de diferentes programas (ou teorias) equivale a nenhuma explicação - a predição é dificultada e corremos o risco de termos apenas explicações ad hoc. (1987, p. 93)

Pires de Oliveira (1999, p. 24), ao apresentar um panorama da história dos estudos semânticos no Brasil e dos diferentes modelos adotados nesse percurso, se coloca mais próxima à sugestão de Tarallo, defendendo que "não é necessário que as diferenças sejam interpretadas como alternativas excludentes, como impossíveis de serem tópicos de uma conversa comum.” Para a autora, "o conhecimento se constrói na conversa na diferença, sem que com isto seja necessário supor um mesmo projeto em comum”.

É nessa direção, favorável à “conversa na diferença”, que entra o quadro sociofuncionalista nos estudos linguísticos brasileiros. Nessa abordagem, a conversa se dá entre a sociolinguística variacionista quantitativa e o funcionalismo linguístico voltado ao estudo da gramaticalização. Paiva (1998, p. 91-92) sintetiza a abordagem sociofuncionalista dizendo que ela

(...) permite incorporar na análise de fenômenos gramaticais nuances semânticas das variantes e o pressuposto de que a forma lingüística sofre restrições impostas pela necessidade de adequação discursiva e pragmática. Faz ressaltar, assim, a importância de aspectos textuais (como distribuição de informação), interacionais e cognitivos (como iconicidade) na distribuição das formas lingüísticas.

Não se retire daí, porém, que essa aproximação teórica específica dê por encerrado o debate acerca da viabilidade de uniões como essa. Entre a teoria da variação e mudança (como também é chamada a sociolinguística variacionista) e o funcionalismo linguístico há diversos pontos conflituosos, que precisam ser considerados para que o casamento traga contribuições significativas para os estudos linguísticos.

Tavares (2003) assume esse papel questionador do casamento sociofuncionalista, levantando e discutindo tanto os pontos em comum quanto os distanciadores das duas abordagens. Após extensa consideração, a autora conclui que a situação atual é de

um imbricamento de convergências e não convergências, conceitos, termos, proposições, interpretações, explicações,metodologias, intertraduções, enfim, temos propostas de casamento diversas, na 'escala teórica' que vai do funcionalismo voltado à gramaticalização à sociolinguística variacionista” (p. 146).

Dentre essas possibilidades, a que Tavares adota em seu estudo da sequenciação retroativo-propulsora de informações em Florianópolis ${ }^{4}$ "envolve um movimento em direção ao funcionalismo, entendendo-se a gramática como emergente” (p. 146). Percebe-se, enfim, a conclusão a que a autora chegou: apesar de ainda não se constituir como um quadro teórico acabado, o sociofuncionalismo é uma perspectiva viável de

\footnotetext{
${ }^{4}$ Cf. Tavares (2003).
} 
pesquisa, que em seu hibridismo possibilita uma aplicação não estanque, maleável de acordo com o objeto e com o os objetivos de pesquisa que se apresentam a esse novo tipo de "linguista camaleão".

Voltemos, contudo, às fontes dessa nova perspectiva, observando como as análises variacionistas tradicionais, ao alargarem o escopo de seu objeto, deram boas-vindas a questões, métodos e explicações funcionais, viabilizando o fazer sociofuncional.

\section{A TEORIA DA VARIAÇÃO E MUDANÇA (TVM)}

A sociolinguística variacionista (também referida por teoria da variação e mudança TVM) vê a mudança nas línguas como motivada por fatores tanto internos quanto externos ao sistema gramatical, ou seja, ela é guiada não apenas por pressões da própria organização interna da língua, mas também por questões sociais e estilísticas. O fenômeno da variação nas línguas também está relacionado a esses fatores, ficando de lado, portanto, noções como a de uma variabilidade caótica ou aleatória nas línguas e entrando em cena o conceito de heterogeneidade ordenada: mesmo na sincronia, a língua não seria um sistema homogêneo de regras, como o queria Saussure, mas uma estância em que ocorre a diferenciação ordenada de formas dentro de uma comunidade de fala. A proposta chomskiana de estudo da competência do "falante ideal em uma comunidade ideal” também é questionada, pois para a TVM um falante nativo tem domínio não só de regras abstratas categóricas, mas de regras variáveis, o que condiz com essa concepção de língua como estrutura heterogênea e inerentemente variável (WEINREICH; LABOV; HERZOG, 1968; LABOV, 1972; 1982; 1994; 2001).

Tem-se, assim, um quadro no qual a variação é concebida como um fenômeno que se pode descrever sistematicamente, considerando-se tanto fatores linguísticos quanto sociais. É aos casos reais de variação que a sociolinguística, portanto, se volta, em sua proposta de ampliação da noção de competência e da aceitação da heterogeneidade ordenada. Há dois requisitos que as formas linguísticas devem cumprir para que sejam consideradas variantes: elas devem veicular o mesmo significado e ser intercambiáveis no mesmo contexto. Desde os primeiros trabalhos de Labov sobre fenômenos variáveis, na década de 1960, a TVM se mostrou bastante produtiva em inúmeros centros de pesquisa (incluindo o Brasil), e tem elucidado questões ligadas tanto ao lado mais "linguístico" do fenômeno de variação e mudança quanto ao político, pois a constatação da sistematicidade e variabilidade em uma língua tem servido para sustentar discussões mais diretamente relevantes em nossa sociedade, como o preconceito linguístico e o ensino de línguas.

\section{A TVM COMO SUPORTE PARA A ANÁLISE DE FENÔMENOS DISCURSIVOS}

De fato a aplicação do método e dos pressupostos variacionistas trouxe novo ânimo a uma área dos estudos da linguagem a que não se dava muita atenção anteriormente - a da relação entre fenômenos de variação e mudança nos diversos níveis gramaticais e a sociedade. Porém, os trabalhos fundadores dessa abordagem abordavam apenas fenômenos variáveis no âmbito da fonologia, onde o conceito de variantes como formas 
que expressam o mesmo significado não é problemático: apesar do significado social que diferenças nesse nível veiculam, não vemos como distintas as referências de ['beyzu] e ['bezu], por exemplo.

Os problemas vêm a partir do momento em que o próprio Labov, em seu estudo sobre a contração e o apagamento da cópula no inglês (LABOV, 1969), estende o domínio de aplicação dos conceitos de variante e de regra variável para a morfologia, o que, de acordo com Milroy e Gordon (2003), deu início a uma tradição nos Estados Unidos de análises de variáveis morfológicas. O estudo sobre a variação de construções passivas no inglês (WEINER; LABOV, 1977) é um exemplo clássico na área, que representa mais uma expansão do aparato teórico-metodológico da sociolinguística, dessa vez para a sintaxe (a polêmica gerada a partir desse trabalho será apresentada brevemente a seguir). Enfim, o que aconteceu gradativamente com a sociolinguística variacionista, não muito depois de sua apresentação à comunidade científica, ao fim da década de 1960, foi a extensão do escopo de seu objeto - das variáveis fonológicas até o nível sintático-discursivo.

Macaulay (2002) faz uma revisão de como tem sido trabalhada a variação no discurso pela sociolinguística. Ele aponta duas abordagens principais nesses estudos: a da observação etnográfica da prática comunicativa, envolvendo a participação do pesquisador na comunidade analisada por algum tempo, para que este observe seus comportamentos e os relacione com sua atividade verbal, e a investigação a partir da perspectiva variacionista, tanto com uma orientação qualitativa, como nos estudos que buscam as diferenças de gênero em narrativas pessoais, quanto quantitativa, de que são exemplos os estudos sobre as tag questions no inglês, por exemplo. Macaulay, porém, vê dificuldades principalmente de cunho metodológico no estudo da variação no discurso: ele chama a atenção para, por exemplo, a necessidade de amostras maiores a fim de que se garanta a ocorrência em bom número de variantes não fonológicas, bem como para problemas na coleta e na determinação precisa das variantes e dos fatores condicionantes. Para o autor, trata-se de um campo em estágio inicial de desenvolvimento.

Como se vê, mesmo entre os que seguem a premissa de que existem variáveis morfossintáticas e discursivas, há desafios a serem superados. Há, ainda, os que sequer aceitam a viabilidade da aplicação da ferramenta sociolinguística a níveis além do fonológico. A partir do já citado estudo de Weiner e Labov sobre as passivas, Lavandera (1978) questiona a aplicação da ideia de mesmo significado para além da fonologia sem que se façam adaptações à teoria. Como dizer que a equivalência entre caixa ['kayfe] e caixa ['kafe] é da mesma natureza que a que percebemos entre destruíram o carro e o carro foi destruído? Há, no segundo caso, nuances de significado que não poderiam simplesmente ser eliminadas ao tratarem-se as formas como variantes. Assim, Labov (1978) responde à crítica de Lavandera com uma adaptação da condição de possibilidade de formas variantes: uma variável estaria configurada se duas ou mais formas representassem não o mesmo significado em todos ou seus aspectos semânticos e pragmáticos, mas apenas “o mesmo estado de coisas”; mantendo-se essa equivalência referencial, podem ser objeto de consideração formas que apresentem traços pragmáticos ou estilísticos distintos. 
Para Tavares (op.cit.), na prática dos estudos variacionistas, todo esse movimento de ampliação do nível de análise da TVM teve como consequência "o afrouxamento do critério pelo qual formas costumavam ser agrupadas, sendo estipulada como quesito para a seleção das variantes uma função discursiva - elas devem ter a mesma função -, ao invés do significado” (p. 103, grifos da autora). A partir daí, foi permitida à sociolinguística a investigação dos contextos favorecedores de uma forma em detrimento de outra no desempenho de uma função discursiva. O que se deu com isso foi que, para dar conta dessa mudança de foco, hipóteses e explicações funcionalistas passaram a figurar nas análises variacionistas, configurando-se assim a intersecção entre funcionalismo e sociolinguística variacionista que atualmente estudamos sob o rótulo de sociofuncionalismo.

Com esse quadro geral brevemente delineado, vejamos agora com mais detalhe em que medida os pressupostos funcionalistas acrescentam ferramentas ao quadro variacionista, fazendo do sociofuncionalismo um casamento promissor.

\section{O BEM-VINDO OLHAR FUNCIONAL}

Um ponto que merece atenção inicial nesta seção, em que levanto alguns pressupostos funcionalistas que podem ampliar o horizonte teórico-metodológico da sociolinguística, é o reconhecimento da relevância de pressões funcionais nos fenômenos de variação e mudança. Tradicionalmente, fatores estruturais, mecânicos, são relacionados a aspectos sociais para a configuração do quadro de condicionadores e de restrições de uso em um caso de variação, e o próprio Labov já defendeu claramente sua preferência às motivações mecânicas na distribuição de formas variantes, criticando uma suposta "superestimação do funcionalismo" em análises variacionistas (LABOV, 1994). Entretanto, já se dispõe de ampla evidência acerca da funcionalidade em fenômenos variáveis. Naro (1998) discute os exemplos usados por Labov em sua crítica ao emprego de hipóteses funcionais nos estudos variacionistas, e observa que se tratavam de "processos antigos em que as forças que determinaram o início do processo de mudança e variação já não estão mais em evidência” (p. 113), situados, portanto, no fim do ciclo funcional proposto por Sankoff (1980), uma etapa em que de fato não se encontra muita funcionalidade. Naro apresenta, então, diversos exemplos de pesquisas sincrônicas realizadas no Brasil em que se atestou a natureza plenamente funcional de fenômenos de variação. Ora, a abordagem sociofuncionalista não despreza essa constatação, e considera em seus estudos da variação tanto as possíveis motivações estruturais quanto funcionais para a escolha de uma forma e não de outra em contextos linguísticos e sociais específicos.

Paiva (op. cit.) salienta, ainda, mais um acréscimo decorrente da aceitação do funcional na variação: a incorporação da dimensão individual de significado das formas variantes, pois,

restringindo o termo equivalência a valor de verdade, é possível postular a existência de variações morfossintáticas e, ao mesmo tempo, depreender as restrições funcionais de alternância entre elas, respeitando, assim, o imperativo de distintividade entre as formas (p. 92). 
Outra aquisição da sociolinguística no encontro sociofuncionalista é o controle mais refinado de grupos de fatores linguísticos, com a incorporação de restrições do âmbito discursivo/pragmático. Deixam de ser levados em conta apenas fatores estruturais (como paralelismo, contexto fonológico ou sintático etc.) e são agregados fatores de ordem funcional como planos discursivos, o status informacional das variantes, graus de integração, entre outros. Essa abertura é bastante natural para o sociofuncionalismo, pois decorre de um ponto naturalmente em comum entre os dois lados da conversa: o princípio de que a língua deve ser estudada a partir de sua manifestação concreta em situações reais de uso.

Não só os grupos de fatores, mas o próprio objeto de pesquisa pode passar a englobar níveis mais discursivos em um estudo sociofuncional. Em Görski et al. (2003), temos alguns exemplos de como fenômenos tipicamente funcionais podem ser incluídos em estudos variacionistas: um deles é a análise dos itens sabe?, não tem? e entende? na função de requisito de apoio discursivo - nesse caso, o grupo de fatores que abarca o foco de atuação dos itens se mostrou significativo para a escolha entre as variantes (cf. VALLE, 2001); quanto à alternância entre quer dizer e vamos dizer na função de reformulação do discurso, as subfunções desempenhadas pelas variantes (conclusiva, esclarecedora ou retificadora) também se mostraram decisivas no uso de uma forma ou de outra (cf. DAL MAGO, 2001).

Os conhecimentos advindos dos estudos da gramaticalização, vinculados em geral a uma perspectiva funcionalista, também enriquecem análises variacionistas. Eles trazem explicações complementares a um caso de variação qualquer, não limitando o estudo ao fenômeno em si, mas trazendo à tona o modo, o processo histórico pelo qual passou cada forma em jogo até o momento em que são situadas pelo analista como variantes competindo pela expressão de um dado significado ou função.

Vale lembrar, ainda, de um certo aspecto do trabalho com a sociolinguística concernente ao tratamento dos dados. Em função da metodologia essencialmente quantitativa de que se vale a sociolinguística no tratamento da variação, é comum que se eliminem da contagem dados ambíguos ou de difícil interpretação, com o objetivo de se evitar enviesamentos estatísticos. Assim, casos que não se encaixem claramente às categorias de controle da análise são muitas vezes simplesmente deixados de lado. $\mathrm{O}$ olhar funcional, atento ao detalhe da diferença formal e à gradiência dos fenômenos gramaticais, traz justamente esses dados para a análise, com igual relevância que os dados mais facilmente atribuíveis a uma categoria. Vê-se, portanto, a língua como uma estrutura maleável, emergente e gradiente, não discreta como a metodologia tradicional da sociolinguística variacionista parece requerer. Creio que a análise ganha, porque nenhum dado precisa ser excluído em benefício da teoria ou da metodologia, e com isso nos aproximamos ainda mais do objetivo comum das duas propostas originais: considerar a língua em situações reais de uso.

Um último ponto é digno de menção neste levantamento dos modos pelos quais a adoção de princípios, hipóteses e métodos funcionalistas pode enriquecer estudos de variação na perspectiva sociofuncionalista: a consideração mais detalhada do aspecto social da variação. Em um estudo variacionista tradicional, grupos de fatores linguísticos são correlacionados geralmente com fatores sociais advindos de uma estratificação básica da comunidade de fala estudada, como sexo, idade e escolaridade 
dos informantes. Essa estratificação social é de certa forma refinada com a entrada de pressupostos tipicamente funcionalistas na análise. Já que questões pragmáticas e interacionais fazem parte da abordagem funcionalista, pode-se ver como decorrente disso um olhar mais atento ao indivíduo e ao modo como este se posiciona em relação a seus pares na comunidade e às variantes a que está exposto, o que amplia ainda mais o leque de ferramentas à disposição do analista ${ }^{5}$.

\section{CONSIDERAÇÕES FINAIS}

Neste artigo pretendi revisar alguns pontos acerca da abordagem teórica de origem dupla que se tem chamado de sociofuncionalismo. Como afirmei na introdução, a posição do autor não é neutra: parto do pressuposto de que o sociofuncionalismo é uma abordagem possível e interessante para o esclarecimento de certos aspectos que, por imposições teóricas ou metodológicas da sociolinguística e do funcionalismo (e aqui tratamos apenas das da sociolinguística), podem não receber o mesmo foco que receberiam se consideradas por essas abordagens isoladamente. A mera impressão, entretanto, não deve ser suficiente, e por isso fez-se aqui uma revisão do debate que está por trás dos "casamentos” teóricos; de como, em linhas gerais, a sociolinguística se volta aos fenômenos da variação e da mudança nas línguas; para que em seguida víssemos como sua proposta foi alargada até o ponto em que já não parece mais possível ignorar as contribuições que um olhar funcional traz, a despeito de Labov, um dos fundadores da sociolinguística e seu teórico de mais destaque. Com esse fundo, o surgimento e a afirmação de uma proposta como a sociofuncionalista não parece apenas viável, mas até esperada.

As contribuições de que falamos, cabe registrar, também são um tanto maleáveis. Para Görski ${ }^{6}$, elas podem ser vistas como associadas ao tipo de fenômeno em estudo: se o objeto se situa em um plano mais discursivo, o instrumental de análise da sociolinguística, mais voltado aos fatores mecânicos, pode ganhar com a colaboração de pressupostos funcionais; se o fenômeno for de fato mais estrutural, talvez 0 funcionalismo não tenha um papel tão relevante como no primeiro caso. Essas alternativas, porém, não devem ser limitadas à divisão estrutural-funcional: ainda há funcionalidade em questões mais "gramaticais" e estruturalidade no nível do discurso. De qualquer modo, constatações como essa servem não como limitação à proposta sociofuncionalista, mas como uma motivação à pesquisa de até que ponto o "casamento" pode ser mantido e em que termos ele será aplicado em função de cada objeto - já que este artigo não pretende mais do que tecer algumas considerações iniciais a respeito da natureza híbrida do sociofuncionalimo e de certos aspectos que parecem positivos na proposta, restando muito ainda por discutir. De acordo com Jackendoff (2007, p. 1), “os desafios mais importantes para a linguística nos próximos anos envolvem fazer mais contato com colegas, com outras abordagens e subdisciplinas

\footnotetext{
${ }^{5}$ São igualmente diversas e relevantes as contribuições que os pressupostos da sociolinguística podem trazer na confluência sociofuncionalista. Há também pontos de conflito entre as duas vertentes, que merecem consideração. Como essas são questões que escapam ao foco deste texto, remeto novamente o leitor a Tavares (2003) e a Görski e Tavares (a publicar) para discussões mais aprofundadas a esse respeito.

${ }^{6}$ Comentário em aula, na disciplina de Sociofuncionalismo, ministrada na UFSC no primeiro semestre de 2009.
} 
dentro da linguística [...]"7. Se levarmos em conta propostas como a do sociofuncionalismo, esses desafios não serão grande problema.

\section{REFERÊNCIAS}

BORGES NETO, J.; MÜLLER, A. L. P. Lingüistas ou camaleões? Uma resposta a Tarallo. D.E.L.T.A., vol. 3, n. 1, 1987.

DAL MAGO, D. Quer dizer: percurso de mudança via gramaticalização e discursivização. Dissertação. Florianópolis: UFSC, 2001.

GIVÓN, T. Syntax: a functional-typological introduction. Amsterdam: John Benjamins, 1984.

GIVÓN, T. English grammar: a funcional-based introduction. Vols. 1 e 2. Amsterdam/Philadelphia: John Benjamins, 1993.

GIVÓN, T. Functionalism and grammar. Amsterdam/Philadelphia: John Benjamins, 1995.

GIVÓN, T. Syntax: an introduction. Amsterdam/Philadelphia: John Benjamins, 2001.

GIVÓN, T. Bio-linguistics: the Santa Barbara lectures. Amsterdam/Philadelphia: John Benjamins, 2002.

GIVÓN, T. Context as other minds: the pragmatics of sociality, cognition and communication. Amsterdam/Philadelphia: John Benjamins, 2005.

GÖRSKI, E. M.; TAVARES, M. A. Teoria da variação/mudança e funcionalismo linguístico: (in)compatibilidades? A publicar.

GÖRSKI, E. et al. Fenômenos discursivos: resultados de análises variacionistas como indícios de gramaticalização. In. RONCARATI, C.; ABRAÇADO, J. (orgs.) Português brasileiro - contato lingüístico, heterogeneidade e história. Rio de Janeiro: 7Letras/FAPERJ, 2003.

HEINE, B. Grammaticalization. In: JOSEPH, B. D.; JANDA, R. D (orgs.). The handbook of historical linguistics. Oxford: Blackwell, 2003.

HOPPER, P. J. On some principles of grammaticization. In: TRAUGOTT, E. C.; HEINE, B. (orgs.). Approaches to grammaticalization. Vol 1: Focus on theoretical and methodological issues. Amsterdam/Philadelphia: John Benjamins, 1991.

\footnotetext{
${ }^{7}$ Tradução minha. No original, se lê: "The most important challenges for linguistics in the coming years involve making better contact with colleagues, with other frameworks and subdisciplines within linguistics, with theories of meaning and conceptualization, with psycholinguistics, with theories of other domains of cognition, with neuroscience, and with education.”
} 
JACKENDOFF, R. A whole lot of challenges for linguistics. Journal of English Linguistics 35, 2007.

LAVANDERA, B. Where does the sociolinguistic variable stop? Language in Society, vol. 7, n. 2, 1978.

LABOV, W. Contraction, deletion and inherent variability of the English copula. Language, v. 45, 1969.

LABOV, W. Sociolinguistic patterns. Philadelphia: University of Pennsylvania Press, 1972.

LABOV, W. Where does the sociolinguistic variable stop? A response to Beatriz Lavandera. Working Papers in Sociolinguistics, vol. 44, 1978.

LABOV, W. Building on empirical foundations. In: LEHMANN, W. O.; MALKIEL, Y. (orgs.). Perspectives on historical linguistics. Amsterdam/Philadelphia: John Benjamins, 1982.

LABOV, W. Principles of linguistic change: internal factors. New York: Academic, 1994.

LAVOV, W. Principles of linguistic change: social factors. Oxford: Blackwell, 2001.

MACAULAY, R. Discourse variation. In: CHAMBERS, K. K.; TRUDGILL, P.; SCHILLING-ESTES, N. (orgs.). The handbook of language variation and change. Oxford: Blackwell, 2002.

MILROY, L.; GORDON, M. Sociolinguistics - Method and Interpretation. Oxford: Blackwell, 2003.

NARO, A. J. Variação e funcionalidade. Revista de Estudos da Linguagem, vol. 7, n. 2, 1998.

NARO, A. J.; BRAGA, M. L. A interface sociolinguística/gramaticalização. Gragoatá: Revista do Programa de Pós-Graduação em Letras. Niterói, n. 9, 2o. semestre, 2000.

NEVES, M. H. M. Estudos funcionalistas no Brasil. D.E.L.T.A., vol. 15, n. especial, 1999.

PAIVA, M. C. Variação e especificidades funcionais no domínio da causalidade. Revista de Estudos da Linguagem, v.7, n.2, 1998.

PAREDES DA SILVA, V. L. Subject omission and functional compensation: evidence from written Brazilian Portuguese. Language variation and change, v. 5, n. 5, 1993.

PIRES DE OLIVEIRA, R. Uma história de delimitações teóricas: 30 anos de semântica no Brasil. D.E.L.T.A., vol. 15, n. especial, 1999. 
SANKOFF, G. Variability and explanation in language and culture: Cliticization in New Guinea Tok Pisin. In: SANKOFF, G. The social life of language. Philadelphia: University of Pennsylvania Press, 1980.

TARALLO, F. Zelig: um camaleão lingüista. D.E.L.T.A., vol. 2, n. 1, 1986.

TAVARES, M. A. A gramaticalização de e, aí, daí e então: estratificação/variação e mudança no domínio funcional da sequenciação retroativo-propulsora de informações um estudo sociofuncionalista. Tese, Florianópolis: UFSC, 2003.

VALLE, C. R. M. Sabe? não tem? entende?: itens de origem verbal em variação como requisitos de apoio discursivo. Dissertação. Florianópolis: UFSC, 2001.

WEINER, J.; LABOV, W. Constraints on the agentless passive. Journal of Linguistics, vol. 19, 1983 [1978].

WEINREICH, U.; LABOV, W.; HERZOG, M. Empirical foundations for a theory of language change. In: LEHMANN, W. P.; MALKIEL, Y. (orgs.). Directions for historical linguistics. Austin: University of Texas Press, 1968. 